\title{
Urban Rail Transit Running Hierarchized Simulation based on Timed Discrete Petri and Matlab under the Background of Industry 4.0
}

\author{
Yue Zhang ${ }^{1}$, , Dengsui Wang ${ }^{2}$, Jianxin Zhou ${ }^{1}$, Xiaowei Shen ${ }^{1}$ \\ ${ }^{1}$ College of Electrical Engineering, North China University of Science and Technology, 063210, \\ Tangshan, China \\ ${ }^{2}$ YishengCollege, North China University of Science and Technology, 063210, Tangshan, China \\ *corresponding author
}

\begin{abstract}
This paper, taking Changchun rail transit as an example, proposes a new method to simulate its running that is hierarchized simulation using timed discrete Petri and Simulink/Stateflow. Firstly, this paper uses the timed discrete Petri nets to build Changchun rail transit line 1-4 running model. And then, based on the timed discrete Petri nets model above, this paper also studies hierarchized simulation model by the tool of Simulink/Stateflow, which consists of two layers: the bottom layer is a single line model, and the top layer is a whole line model. In order to realize the rail transit running visualization, the tool of Matlab/App Designer is employed to design monitoring interface for Changchun rail transit line 1-4. This method is scalable and popularized.
\end{abstract}

Keywords: Urban rai transit, Timed discrete Petri, Simulink/Stateflow, Matlab/App Designer, Running Simulation, Industry 4.0

\section{Introduction}

Nowadays, rail transit has become an important driving force for urban development. Rail transit can effectively solve urban traffic problem and improve travel quality. It has very important practical significance for urban rail transit to analyze running process of rail transit. Firstly, in the urban rail transit planning and construction stage, it can monitor various parameters in running process, and provide data basis for the choice and design of rail transit line. Secondly, it provides great convenience to the citizens. The arrival display function eliminates the pain of waiting at the platform and improves the efficiency of waiting for citizens. Thus, citizens can reasonable arrangement of travel planning and improve the happiness index. Finally, through the simulation of rail transit running process, the main factors affecting rail transit operation are analyzed, thereby improving the operation scheme and service quality of urban rail transit [1].

\section{Relevant Literature}

The train running calculation and simulation method started earlier at abroad. The most famous of them are RailSim, Train Performance Calculator (TPC), Train Operations Mode (TOM), Train Operation and Energy Simulator (TOES), and Train Energy Model (TEM) in USA; VIS10N in Britain; Railsys in Germany; TrainStar in Europe; Universal Train Simulator (UTRAS) in Japan; OpenTrack in Switzerland and so on. And the most popular used are TOM, Railsim, Railsy and OpenTrack [2]. These train running calculation and simulation software can also be applied to rail transit and metro running simulation. For example, OpenTrack is used to simulate the operation scale and operation mode of Beijing Yanfang line by Liu Pengao from Beijing Jiaotong University [3]. It can be seen that rail transit simulation software has been mature and widely used at abroad.

There are many methods and tools to develop simulation software in China. Virtual Driving Simulation System: this system uses three-dimensional image technology combined with the virtual instrument technology to train metro drivers, and possesses visual driving platform with 3D visual view [4]. Vehicle Subsystem of the Fully Automatic Operation System: with Visual Studio 2015 as main development tool, this system designs the ISSN: 0010-8189

(C) CONVERTER 2020

www.converter-magazine.info 
simulated ATS system, namely simulation control center, and displays the function of train running [5]. Ref [6] carried out the simulation of train-carried equipment with Visual C++ language. Driver Manipulate Interface was designed and computerized calculation method, including the traction, resistance, braking force and resultant force of the train, was anaylzed. Ref. [7] utilized the graphical programming features of LabVIEW and mathematical operation functions of MATLAB to realize the simulation calculation of metro running. Some universities in China have their own urban rail transit laboratories, for example, simulation center in Southwest Jiaotong University [8].

At present, the most popular APP of real-time bus query in mobile phone have the functions of routes and stations real-time query for bus, subway and metro, such as NYC Subway in USA; Citymapper, Bus Time, Bus London in Britain; PTV, TripView Sydney in Australia and Metro map, Transit in Canada. The widely popular APP in China areMyBus, BusAssistant, bus Intelligent on Line and so on. All the APP mentioned above can provide the realtime location information of the concerned bus anytime and anywhere by mobile phone. It helps passengers to optimize trip plan and improve travel efficiency.

The combined simulation method of Petri nets and Matlab/Stateflow have been widely used in various industries, such as intersection and on/off-ramps simulation in urban traffic [9], availability assessment of railway signaling systems [10], batch chemical and biochemical plants process simulation [11], the cost evaluation of maintenance activities in multi-factory production [12]. But this method used in rail transit running and monitor has not been reported in references.

Firstly, this paper, taking Changchun rail transit line 1-4 as an example, proposes a hierarchized timed discrete Petri net model (HTDPM) to establish Changchun rail transit line 1-4 running process. The route map of Changchun rail transit line 1-4 is shown in Fig.1. And then, Simulink/Stateflow model is established to simulate scheduling and running of rail transit. Finally, matlab/App Designer is used to minor running states, which is helpful to manage and display for rail transit. The method of this papers has strong realizability and generalization, and has a wide range of practical prospects, because it is simple and effective.

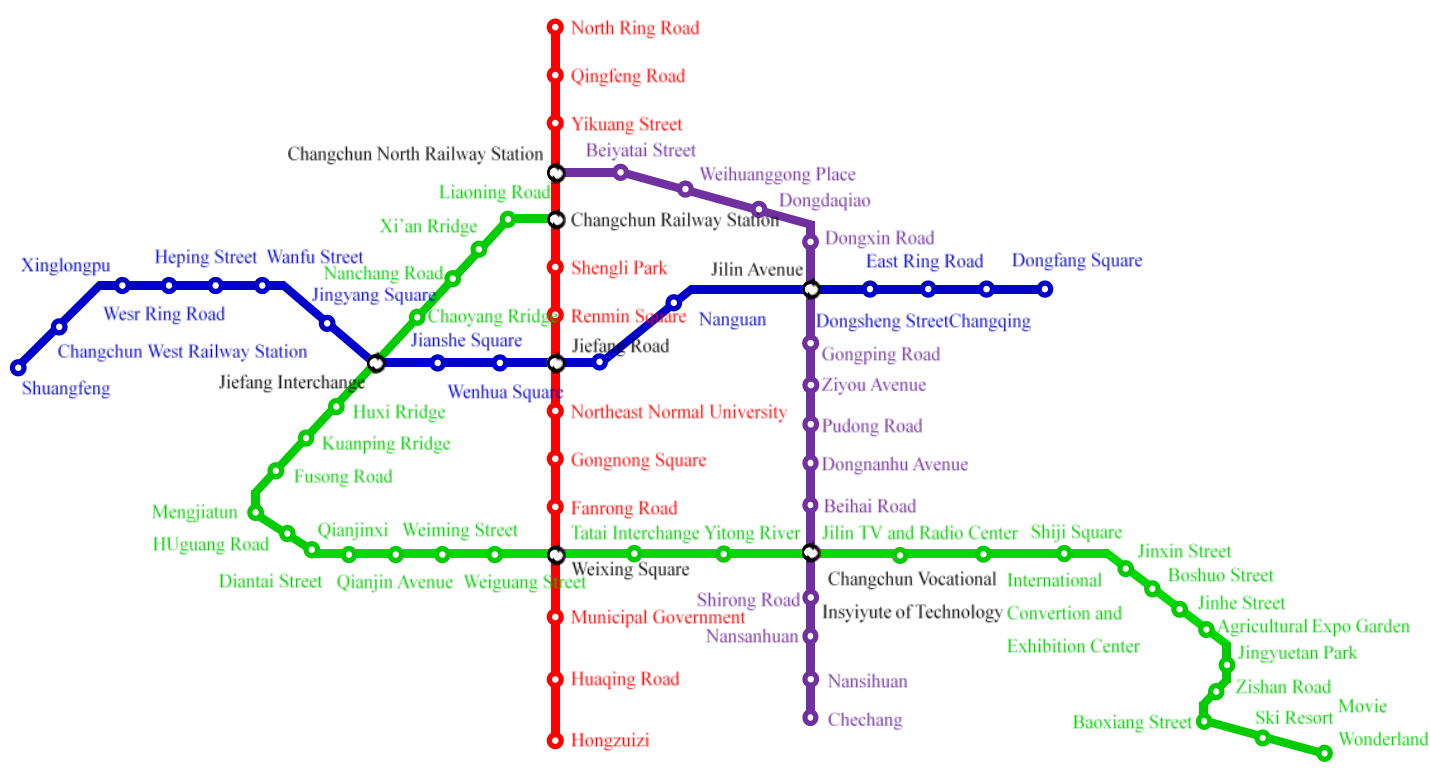

Fig 1: Route Map of Changchun Rail Transit Line 1-4.

\section{HTDPM for Changchun Rail Transit}

HTDPM for Changchun Rail Transit divides into two hierarchizes, namely HTDPM Down (HTDPM-D) and HTDPM Top (HTDPM-T). HTDPM-D can further divide into HTDPM-D up line (HTDPM-D I ) and HTDPM-D

ISSN: 0010-8189

(C) CONVERTER 2020 
down line (HTDPM-D II ).

\subsection{HTDPM-D I Formal Definition Presentation}

HTDPM-D I of Changchun rail transit is defined as a seven-tuple, that is, HTDM-D $I=\left\{\mathrm{P}^{\mathrm{D}}, \mathrm{T}^{\mathrm{D}}, t\right.$, Pre, Post, Token, I\}.

$\mathrm{P}^{\mathrm{D}}=\left\{P_{1}^{D}, P_{2}^{D}, \cdots, P_{N}^{D}\right\}:$ Discrete places set, represented by "O”, which describes the arrival states of the metro. Here, $\mathrm{N}$ is the total number of the platform, for example, $\mathrm{N}=15$ for Changchun rail transit line 1.

$\mathrm{T}^{\mathrm{D}}=\left\{T_{1}^{D}, T_{2}^{D}, \cdots, T_{N-1}^{D}\right\}$ : Discrete transitions set, represented by "प", which describes the change of metro from the previous platform to the next platform.

$t$ is defined as delay time attached to the $\mathrm{T}^{\mathrm{D}}, \mathrm{t}=\left\{T_{1}^{D}\left(t_{1}\right), T_{2}^{D}\left(t_{2}\right), \cdots, T_{N-1}^{D}\left(t_{N-1}\right)\right\}$ : Non-negative rational numbers set, which describes running time of the metro between two adjacent platforms.

Pre is the input incidence arcs set. When no value is indicated on the arc, the default weight value is 1 . The symbol "O $\rightarrow \square$ " means the metro departs from the current platform.

Post is the output incidence arcs set. When no value is indicated on the arc, the default weight value is 1 . The symbol " $\square \rightarrow O$ " means the metro arrives at the current platform.

Token is the number of marks in $\mathrm{P}^{\mathrm{D}}$. Token $=\left\{P_{1}^{D}\left(\right.\right.$ Token $\left._{1}\right), P_{2}^{D}\left(\right.$ Token $\left._{2}\right), \cdots, P_{N}^{D}\left(\right.$ Token $\left.\left._{N}\right)\right\}$ : Non-negative rational numbers set, which describes number of metros currently in running. If Token is a full zero vector, it means the metro is in a state of shutdown, and the initial default value is this state. If the Token in a $\mathrm{P}^{\mathrm{D}} \geq 2$, it means that two or more metros are running at the current platform. Obviously, the running state is wrong. Tokens can also be used for status identification.

I is defined as information marker attached to metro, which is used in displaying the basic information of current metro, such as metro number, running direction, the next platform, the terminal station and so on.

\subsection{Abstraction for HTDPM-D II}

Abstraction for HTDPM-D II is as follows: (1) the modeling method of HTDPM-D II is same as HTDPM-D I, the only difference is that it runs in the opposite direction; (2) the delay time between HTDPM-D I and HTDPM-D II is the turn back time of the metro; (3) the running rules of HTDPM is the same as the timed discrete Petri nets; (4) up line metro timetable information is shown in Table 1, where the values of the first metro time, last metro time and interval time can reset.

Table 1 Up Line Metro Timetable Information

\begin{tabular}{|c|c|c|c|c|}
\hline Line & Line1 & Line2 & Line3 & Line4 \\
\hline Origin Station & North Ring Road & Shuangfeng & $\begin{array}{c}\text { Changchun Railway } \\
\text { Station }\end{array}$ & $\begin{array}{c}\text { Changchun North } \\
\text { Railway Station }\end{array}$ \\
\hline Terminal Station & Hongzuizi & Dongfang Square & Wonderland & Chechang \\
\hline First MetroTime & $05: 50$ & $05: 55$ & $06: 00$ & $06: 00$ \\
\hline Last Metro Time & $21: 30$ & $21: 30$ & $20: 00$ & $21: 00$ \\
\hline Interval Time & $7 \mathrm{~min}$ & $8 \mathrm{~min}$ & $10 \mathrm{~min}$ & $8 \mathrm{~min}$ \\
\hline Total Time & $30 \mathrm{~min}$ & $38 \mathrm{~min}$ & $38 \mathrm{~min}$ & $30 \mathrm{~min}$ \\
\hline $\begin{array}{c}\text { Total Metro in } \\
\text { Running }\end{array}$ & 10 & 10 & 14 & 8 \\
\hline
\end{tabular}

\subsection{HTDPM-D Graphical Definition Presentation}

This paper takes Changchun rail transit line 1-4 as an example, and here takes Changchun rail transit line 1 as an example for modeling. The whole running time of line 1 is 1 hour, including up line and down line time 30 min

ISSN: 0010-8189

(c) CONVERTER 2020 
each. Ignoring the return back time (counted as 0 min here), the departure time is 7 min, and at least 9 metros are needed. Taking the First Metro Time 05:50 as the simulation starts time, the HTDPM-D for Changchun rail transit line 1 at $25 \mathrm{~min}$ is shown in Fig.2.

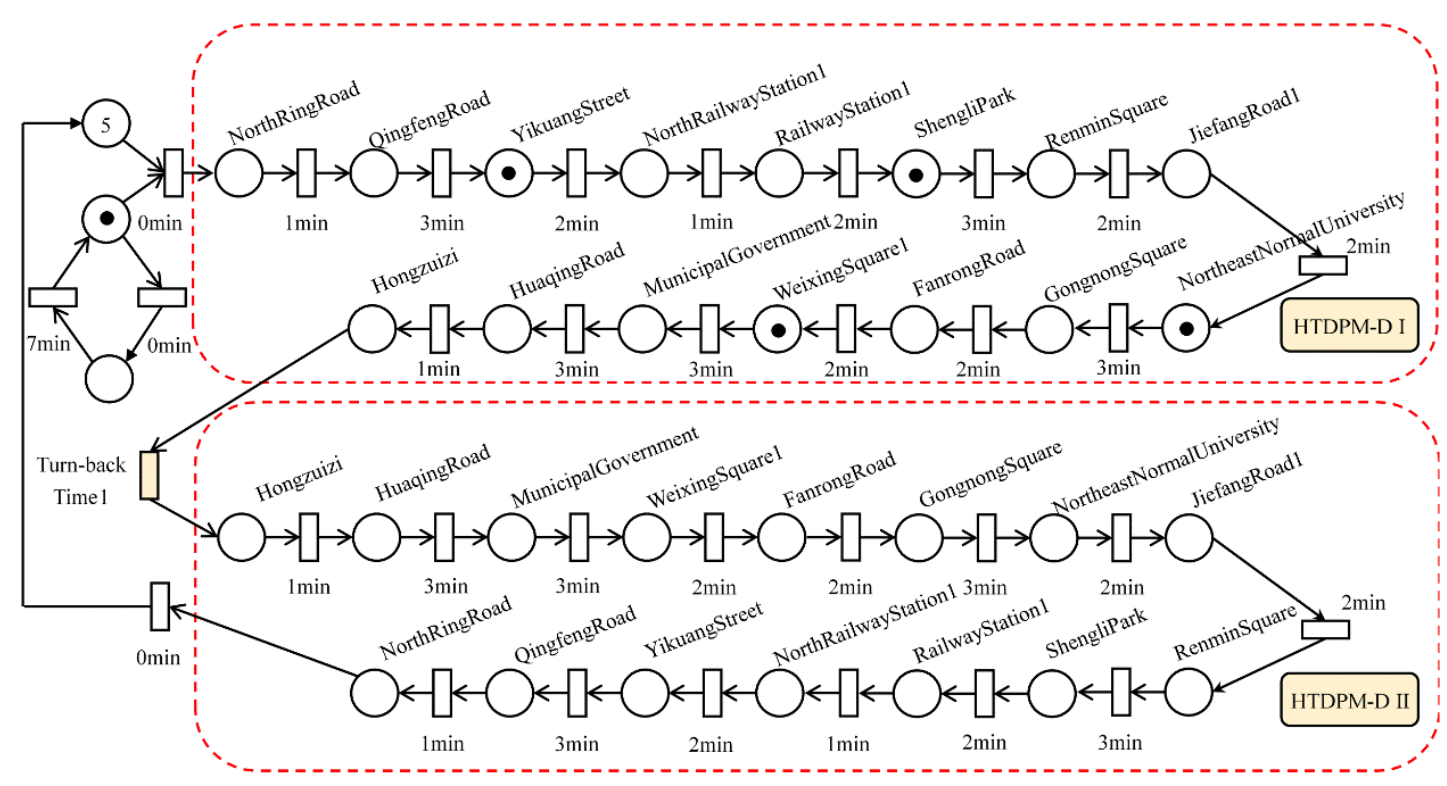

Fig 2: The HTDPM-D for Changchun Rail Transit Line 1 at 25 min.

\subsection{HTDPM-T Graphical Definition Presentation}

HTDPM-T is a whole model, and HTDPM-T for Changchun rail transit line 1-4 at 25 min is shown in Fig. 3.

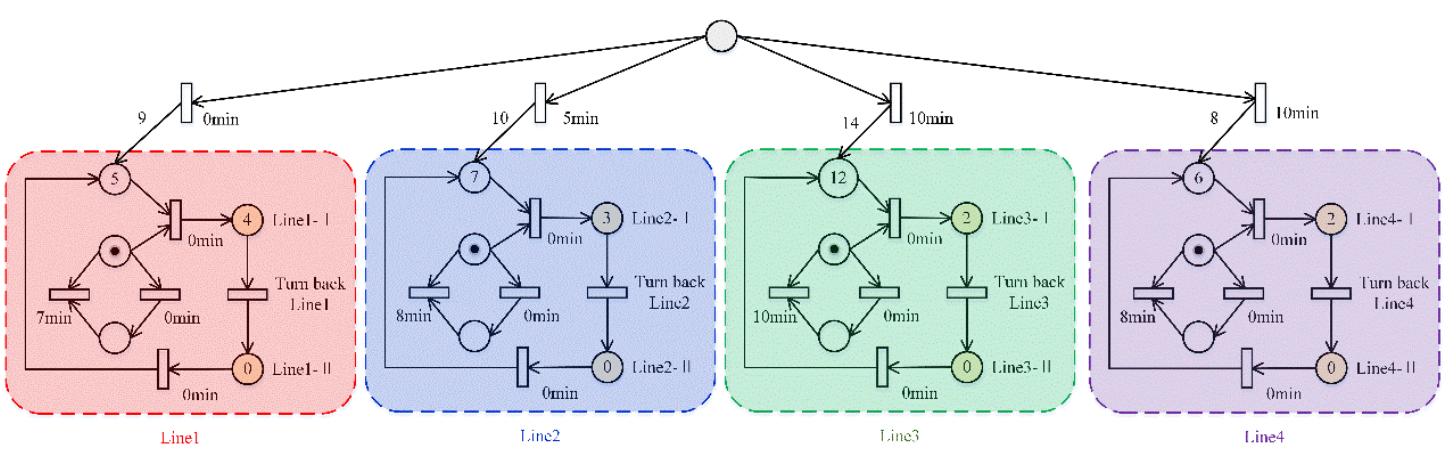

Fig 3: HTDPM-T for Changchun rail transit line 1-4 at 25min.

\section{Simulink/Stateflow Model}

\subsection{Correspondence between HTDPM and Simulink/Stateflow}

The tools of Stateflow can be used to running HTDPM, and the key technology is to find the corresponding relationship between HTDPM and Stateflow model, which is shown in Table 2.

Table 2 Correspondence between HTDPM and Simulink/Stateflow Model

\begin{tabular}{|c|c|}
\hline HTDPM Elements & Stateflow Elements \\
\hline Discrete Places Seto & States $\square$ \\
\hline Place Name, for example, & State Name, for example, \\
RailwayStation & RailwayStation \\
\hline Discrete Transitions Set $\square$ & Transition $\rightarrow$ \\
\hline
\end{tabular}

ISSN: 0010-8189 


\begin{tabular}{|c|c|}
\hline Input Incidence Arcs Seto $\rightarrow \square$ & \\
\cline { 1 - 1 } Output Incidence Arcs Set $\square \rightarrow 0$ & \\
\cline { 1 - 1 } Delay Time, for example, $1 \mathrm{~min}$ & $\begin{array}{c}\text { Temporal Logic, for example, } \\
\text { after(1,CLK) }\end{array}$ \\
\hline Information Marker: Token & Active State \\
\hline
\end{tabular}

\subsection{HTDPM Stateflow Model}

Stateflow model corresponding to HTDPM-D I of Fig.2 is shown in Fig.4. In Fig.4 each state represents a metro with the number from Line1_001 to Line1_004. Currently active sub-state in a state represents the metro arriving at the platform, and its "State Output" Property set to "Create data for monitoring self activity". In other words, when the metro arrives at the platform, the active sub-state value is 1. For example, No. Line1_002 metro is arriving at northeast normal university station at $25 \mathrm{~min}$, and its state output value is 1 , while other state output values are 0 . This Boolean value is used to display metro running status in App Designer.

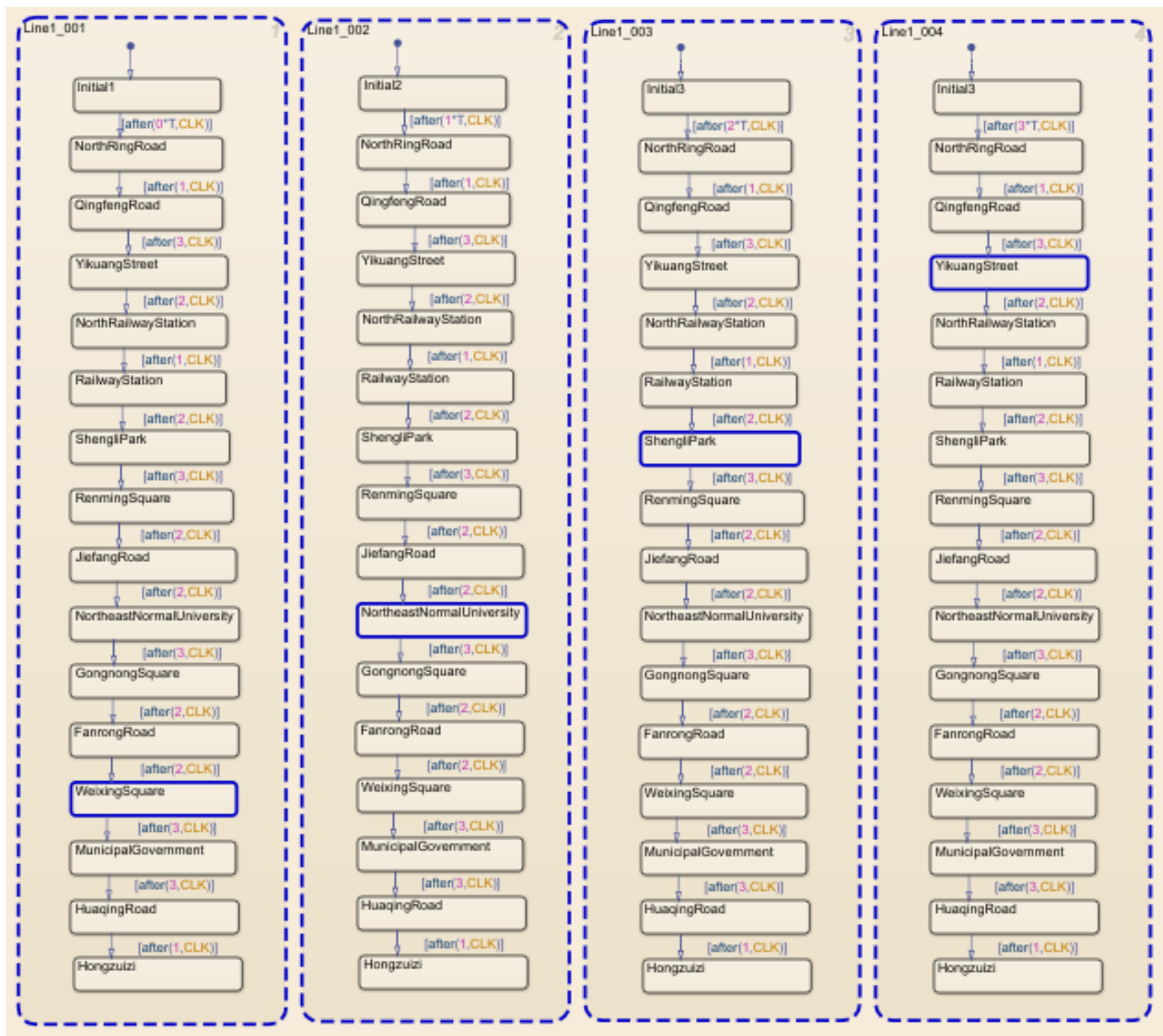

Fig 4: HTDPM-D Stateflow Model for Changchun Rail Transit Line1 at 25min.

The key technology are as follows. (1) the four states named LINE1_001 to LINE1_004 are in a Parallel state, not Exclusive state. (2) temporal logic is based on CLK=1 $\mathrm{min}$; (3) the state of metro reaching platform is set to boolean value 1 .

\subsection{HTDPM-T Simulink Model}

ISSN: 0010-8189

(C) CONVERTER 2020 
HTDPM-T Simulink Model for Changchun rail transit line 1 corresponding to Fig.2 and Fig.4 is shown in Fig.5.

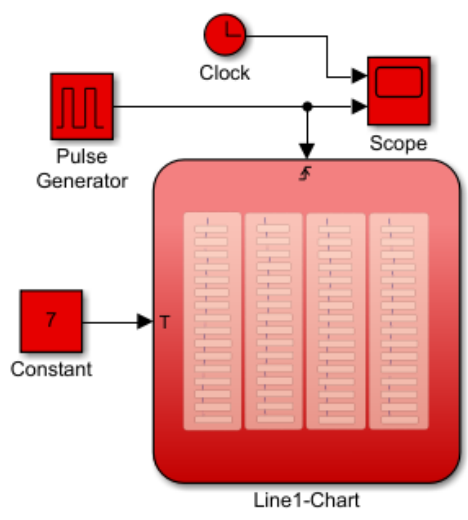

Fig 5: HTDPM-T Simulink Model for Changchun rail transit line 1

HTDPM-T Simulink Model for Changchun rail transit line 1-4 is shown in Fig.6.

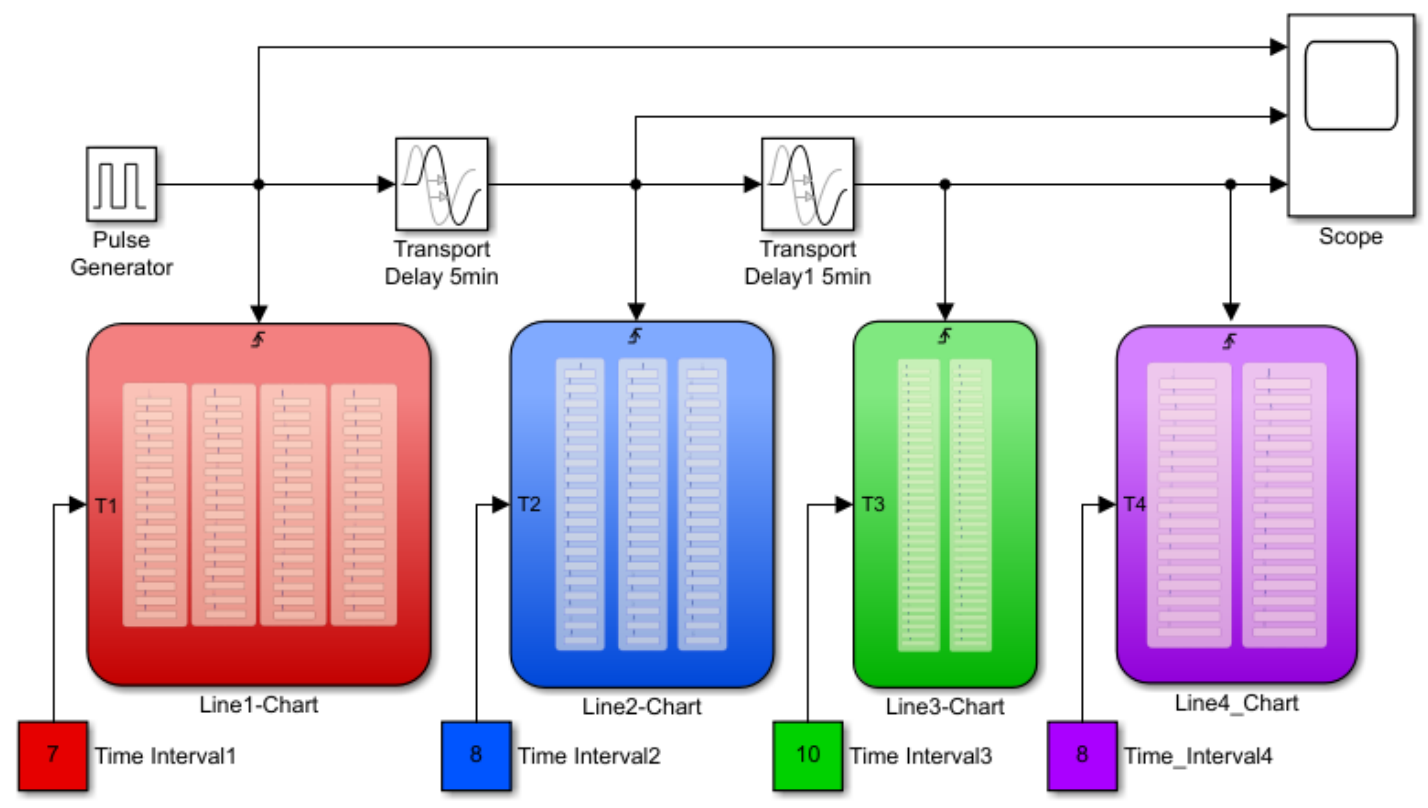

Fig 6: HTDPM-T Simulink Model for Changchun rail transit up-line 1-4.

\section{Graphical User Interface Design}

In order to motor rail transit running status, Matlab/App Designer is used to design graphical user interface (GUI). The key technology for graphical visualization are as follows: (1) Route map of Changchun rail transit line 1-4 shown in Fig.1 is loaded in images, which is a component in Matlab / App Designer. (2) The Lamp component is used to display the metro running status by changing the color of lamp. The motoring GUI for Changchun rail transit up-line 1-4 is designed in Fig.7. The number of metros and their specific locations are marked on routes. A red light on the line indicates that the metro has arrived at current platform, while a green light indicates that the metro has not arrived. (3) Simulation data used in lamp component comes from sub-state in state flow model.

ISSN: 0010-8189 


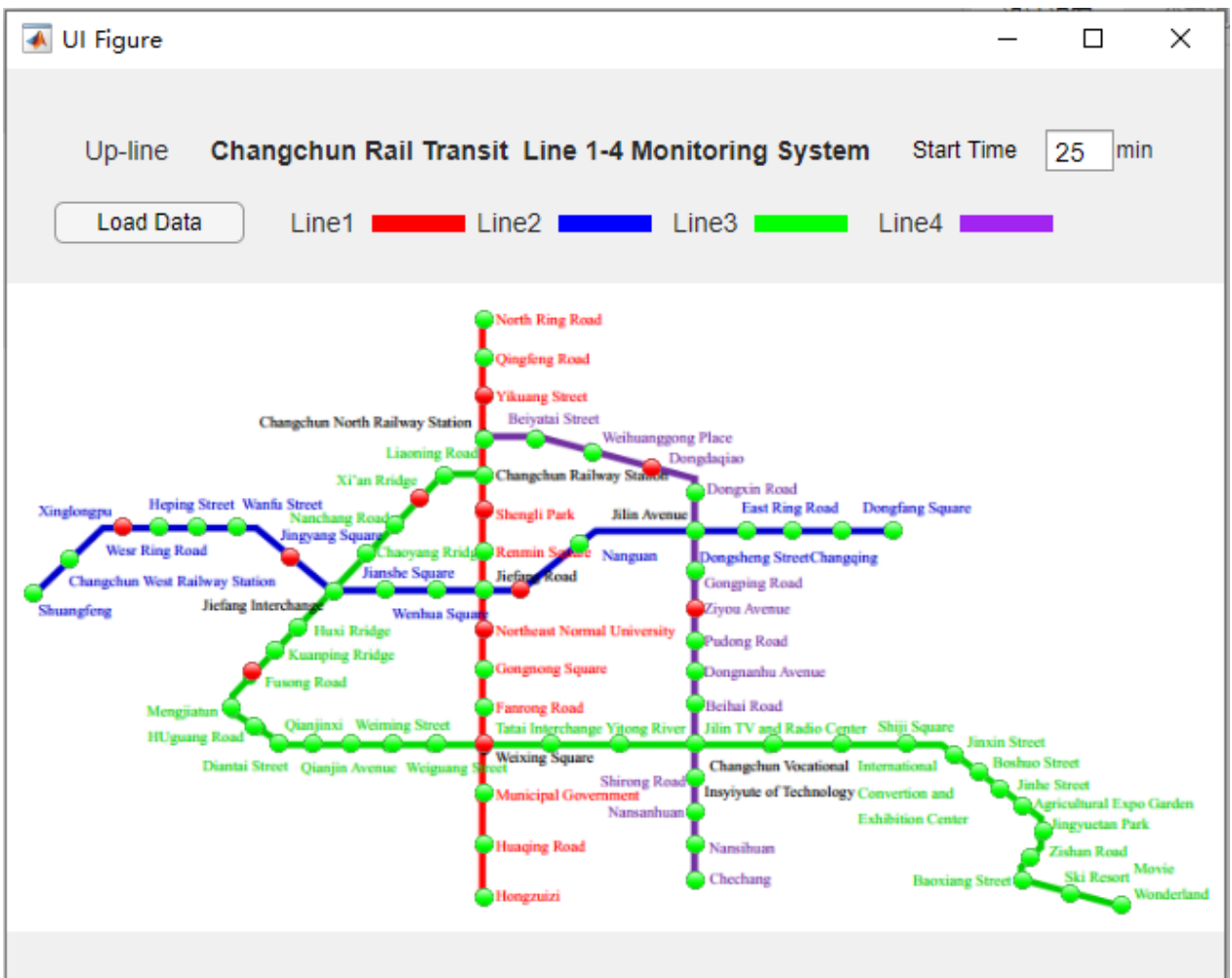

Fig 7: Changchun Rail Transit Up-Line 1-4 Monitoring System

\section{Conclusion}

This paper first surveyed application software for calculation method of train running simulation, widely popular real-time bus query mobile phone software at present, application of Petri net and Stateflow simulation method. And then Timed Discrete Petri net is employed to model rail transit running by the tool of Stateflow. And it is a hierarchized simulation method. Finally, it adopts MATLAB/APP Design to monitor the rail transit running based on the APP software of my Bus. This method is based on Changchun rail transit Line 1-4 as an example, and it can be promoted to the subway, bus and train systems of other cities. It can also be used as a teaching case for course of computer-aided modeling and simulation.

\section{Acknowledgements}

This work is supported by industry-university-research of cooperative education project for ministry of education in China (Grant: 201902062045, Grant: 201902056008).

\section{References}

[1] X. X. Wang, J. Wei, Study on Train Operation Simulation of Urban Rail Transit. Journal of Shandong Industrial Technology. 2018, (9):59-59

[2] H. H. Fang, C. Wang, Review and Assessment of Railway Operational Simulation Systems. Value Engineering, 2018, 37(31):239-242

[3] P. A. Liu, Operationalsafety analysis and train running simulation of Fully Automated Operation urban rail transit. Beijing Jiaotong University, 2017

[4] H. P. Ye, J. Yao, X. J. Qian, Virtual Driving Simulation System for Urban Rail Transit. Urban Mass Transit, 2015, 18(11):124-126

[5] X. Chen, Research on the Simulation Platform of the Vehicle Subsystem of the Fully Automatic Operation System. Lanzhou Jiaotong University, 2018

[6] L. Wang, Research On the Train-carried Subsystem Simulation System of CTCS3. Southwest

ISSN: 0010-8189

(c) CONVERTER 2020 
JiaotongUniversity, 2009

[7] B. J. Xue, Simulation calculation of subway operating parameters based on Labview and Matlab. Technology and Economic Guide, 2016, (22):19-21

[8] X. M. Zhang, G. Y. Lu, B. S. He, etal. Study of experiment teaching based on urban rail transit dispatching command simulation system. Laboratory science, 2019, 22(3):134-138

[9] Francesco. Basile, Pasquale. Chiacchio, Domenico. Teta, A hybrid model for real time simulation of urban traffic. Control Engineering Practice, 2012, 20(2):123-137

[10] Qiu S, Sallak M, W. Schön, et al. Availability assessment of railway signalling systems with uncertainty analysis using Statecharts. Simulation Modelling Practice and Theory, 2014, 47:1-18

[11] Bhner F D, Prado-Rubio O A, Huusom J K. Discrete-Continuous Dynamic Simulation of Plantwide Batch Process Systems in MATLAB. Chemical Engineering Research and Design, 2020, 159:66-77

[12] Simeu-Abazi Z, Ahmad. A. A. Optimisation of distributed main tenance: Modelling and Application to the multi-factory production. Reliability Engineering \& System Safety, 2011, 96(11):1564-1575. 